\title{
Burr Edge Occupancy: An Edge Finishing Index for Milling Machined Parts
}

\begin{tabular}{|r|l|}
\hline Journal: & Transactions of the Canadian Society for Mechanical Engineering \\
\hline Manuscript ID & TCSME-2018-0066.R1 \\
\hline Manuscript Type: & Article \\
\hline Author: & Co-Jun-2018 \\
\hline & $\begin{array}{l}\text { Complete List of Authors: } \\
\text { of Mechanical Engineering; Ecole Polytechnique de Montreal, Mechanical } \\
\text { Tiabiz; Ecole de technologie superieure, Mechanical Engineering } \\
\text { Songieene, Victor; Ecole de technologie superieure, Mechanical }\end{array}$ \\
\hline Keywords: & Burr, Deburring, Edge finishing, Machining, Slot Milling \\
\hline $\begin{array}{r}\text { Is the invited manuscript for } \\
\text { consideration in a Special } \\
\text { Issue? : }\end{array}$ & Not applicable (regular submission) \\
\hline &
\end{tabular}

\section{SCHOLARONE Manuscripts}




\title{
Burr Edge Occupancy: An Edge Finishing Index for
}

\section{Milling Machined Parts}

\author{
Seyed Ali Niknam ${ }^{*}$, Azziz Tiabi ${ }^{2}$, Victor Songmene ${ }^{2}$
}

${ }^{1}$ Sustainable Manufacturing Systems Research Laboratory, School of Mechanical Engineering, Iran University of Science and Technology, Tehran, Iran; saniknam@iust.ac.ir

${ }^{2}$ Mechanical Engineering Department, École de Technologie Supérieure, Montréal, Canada. azziz.tiabi.1@ens.etsmtl.ca; victor.songmene@etsmtl.ca

*Corresponding author

\begin{abstract}
Machining burrs are formed wherever is an edge. One of the useful solutions to decrease the machining time and cost, in particular when dealing with milling parts is to generate the machined parts edges with minimum burr. To this end, this article proposes burr edge occupancy $\eta_{\mathrm{s}}$ as an index to evaluate the deburring difficulty and consequently adequate selection of suitable deburring methods. Therefore, it is initially required to evaluate the sensitivity of $\eta_{\mathrm{s}}$ to cutting parameters. To that end, the main governing factors on $\eta_{\mathrm{s}}$ were investigated when slot milling two types of aluminium alloys in the automotive and aerospace industries that belong to different families. The cutting parameters that led to edges with minimum $\eta_{\mathrm{s}}$ were presented. It was found that unlike the most of the burr size attributes, the $\eta_{\mathrm{s}}$ is sensitive to the variation of cutting parameters used, in principle cutting speed, family of material and cutting tools. In fact, lower $\eta_{\mathrm{s}}$ means less time and efforts for deburring and edge finishing of machined parts. Furthermore, this should be underlined that $\eta_{\mathrm{s}}$ measurement is more convenient than the procedures used to measure other burr size attributes, including burr height $\left(b_{h}\right)$ and burr thickness $\left(b_{t}\right)$.
\end{abstract}


Keywords: Burr, Deburring, Edge finishing, Machining, Slot Milling. 


\section{Introduction}

Due to global competition, the machinability attributes such as tool life, chip characteristics, chip disposal, surface finish and burr formation are of major concern when dealing with high precision machining (Niknam et al. 2014a). The presence of the latter tend to affects the work part quality and precise accuracy of the deburring processes (Songmene et al. 2013; Niknam et al. 2014b). Up until now, the machinability attributes of several easy to difficult to cut materials, in particular, burr formation mechanism and morphology in brittle and ductile materials are very well understood, and sophisticated approaches for adequate prevention and minimization were introduced (Chen et al. 2006; Niknam et al. 2012; Gillespie et al. 1976; Nakayama et al. 1987; Ko et al.1991; Dornfeld et al.2004; Lauderbaugh 2009; Lekkala et al. 2011; Niknam et al. 2014c). However, it is to note that the aforementioned approaches are however mostly limited to material and operational conditions used. Knowing that over 100 deburring processes were proposed so far (Gillespie 1999), comprehensive investigations on factors governing deburring selection which in fact tend to minimize the nondesirable expenses are strongly advised. Among machining operations, milling burr formation morphology is very complex. However, fundamental aspects of burr formation, as well as milling burr size minimization have been reasonably understood (Hashimura et al. 1995; Olvera et al. 1996; Lin 2000; Chern 2006; Biermann et al. 2010; Niknam et al. 2013a) and several solutions including experimental characterization and analytical modeling approaches were presented (Aurich et . 2009; Niknam et al. 2014a; Niknam et al. 2015. However, among milling operations, slot milling (Figure 1) has a very complex burr shape and formation mechanism which may pose complex difficulties during deburring operations (Niknam 2013; Niknam et al. 2014d). In fact, slot milling burrs could be large or small, even not visible with naked eyes (Figure 2). It is therefore recommended to limit and control the burr size and morphology, otherwise secondary operations so- called as deburring which are time-consuming and expensive are needed. Unfortunately, except limited studies which were 
mostly conducted by the authors (Niknam et al. 2013a; Tiabi 2010; Niknam et al. 2013b) and (Luo et al.2008), low amount of information is available about the factors governing slot milling burrs.

In fact, to gain an adequate burr description, a new term, called "burr value", comprises several burr size attributes (Figure 3) was proposed (Schäfer 1975). As noted in (Rangarjan 2005), the most widely used burr size attributes are burr height $\left(b_{h}\right)$ and thickness $\left(b_{t}\right)$ which in principle are widely used for tool replacement, schedule arrangement, and evaluation of the burr removal difficulties. According to (Niknam et al. 2013c), the longitudinal profile of the burr is not commonly used to define the burrs as it is not highly informative in most cases. Instead, the burr thickness $\left(b_{t}\right)$ is frequently used to determine deburring time and methods (Aurich et al. 2009; Niknam et al. 2014a). However, as noted in numerous studies (Niknam et al. 2013; Niknam et al. 2014; Niknam et al. 2014; Niknam et al. 2015; Niknam et al. 2017), due to complex interactions between cutting process parameters, a direct relationship can not be formulated between cutting parameters and burr size attributes. Furthermore, adequate measurement of the burr thickness is considered as a timeconsuming approach which requires high resolutions cameras and SEM machines. This, in fact, poses significant difficulties when predictive modeling of burr size attributes are demanded (Niknam et al. 2013b; Iwata et al. 1984; Kloche et al. 2004; Leopold et al. 2010; Lekkala et al. 20111; Niknam 2013). According to (Narayanaswami et al. 1994), the burr location and length, work part edges as well as material to be deburred are other critical factors on deburring complexity (Gillespie 1999). However, In order to investigate the adequate solutions to achieve edges with minimum burrs, an innovative index, so-called burr edge occupancy $\eta_{\mathrm{s}}($ Eq.1) is proposed in this work, which not only incorporates the effects of critical factors on deburring selection, but also, it does not require the time-consuming burr size measurement tasks. 


\section{Theoretical Base}

As noted in (Niknam et al. 2014d), only five slot milling burrs (Figure 1) are visible with naked eyes. Even though, adequate measurement of the burr size attributes $\left(b_{t}, b_{h}\right)$, associated to each slot milling burr (Figure 1) is complex and time-consuming. To remedy the lack of knowledge aforementioned, the burr edge occupancy $\eta_{s}$ is proposed as an innovate parameter which can be used for precise selection of deburring operations, incorporating the presence of all burrs. As shown in Eq.1, $\eta_{\mathrm{s}}$ represents a percentage of the edges occupied by the burrs (Figure 4) as follows:

$$
\eta_{s}=\frac{\sum_{i=1}^{6} l_{i}}{\sum_{i=1}^{6} L_{i}} \times 100
$$

Where:

$l_{i}$ : represents the length of burrs occupation on the edge $i$

$L_{i}$ : represents the length of edge number $i$

The burr edge occupancy $\eta_{\mathrm{s}}$ in Eq. 1 covers six edges in milled slot parts. To attribute value to $l_{i}$, burrs should have at least a minimum height of $0.1 \mathrm{~mm}$. The logic behind burr edge occupancy $\eta_{\mathrm{s}}$ denotes that higher $\eta_{\mathrm{s}}$ means more efforts demanded to browse the machined part edges towards adequate burr removal and edge finishing. In fact, lower $\eta_{\mathrm{s}}$ means less time and efforts for deburring and edge finishing of machined parts. It should be underlined that burr edge occupancy $\eta_{\mathrm{s}}$ measurement is more convenient than the procedures used to measure other burr size attributes, including burr height $b_{h}$ and burr thickness $b_{t}$. It can be considered as the main potential elements, encouraging further investigations on this subject. To that end, the following experimental tests were conducted to 
evaluate the factors governing $\eta_{\mathrm{s}}$. In fact, higher sensitivity of $\eta_{\mathrm{s}}$ to the variation of cutting parameters reflects the adequacy of the proposed index in Eq.(1).

\section{Experimental plan}

As shown in Table 1, the multi-level full factorial design of experiment was used in this work, and dry slot milling tests were conducted on AA 2024-T351 and AA 7075-T6 work parts using a 3-axis CNC machine and a carbide cutting tool $(\mathrm{D}=19.05 \mathrm{~mm})$ under dry condition. The overview of the mechanical properties of the tested work parts is presented in Table 2. The experimental works consisted of five controllable cutting parameters as listed in Table 1. The experimental works were repeated twice, and the average values of responses were considered for analysis. In total, 324 milling tests were necessary to complete the study. A 3-axis CNC machine tool (Power: 50kW, maximum speed: $28000 \mathrm{rpm}$; Torque: $50 \mathrm{Nm}$ ) was used in milling tests (Figure 5a). A slot milling tool with three flutes $Z=3$ and tool diameter D $19.05 \mathrm{~mm}$ were used (Figure $5 \mathrm{~b}$ ).

\section{Result and discussion}

\section{Method of analysis}

Statistical tools such as Pareto chart and surface response models were used to investigate the factors governing burr edge occupancy $\eta_{\mathrm{s}}$ when slot milling 7075-T6 and 2024-T351 aluminium alloys. The overview of statistical methods used is presented in (Niknam et al. 2013d). Among empirical modeling approaches, the multiplicative model was used.

\section{Results}

The first considerations of the burr formation refer back to chip formation, as the burr formation mechanism is highly affected by chip formation mechanism. It is agreed upon that feed rate, depth of 
cut, cutting speed and tool geometry are the main controlling parameters on milling burr formation morphology and size (Korkut et al. 2007). In fact, burr size minimization can be conducted by using adequate strategies leading to the transition of primary burrs to secondary burrs (Niknam 2017). It is therefore required to identify the factors governing burr formation according to the type of material and machining operation used. To that end, statistical tools as aforementioned were used. Pareto charts and the main effect plot of $\eta_{s}$ are shown in Figure 6. It can be underlined that cutting tool (A), cutting speed (E), material (A), depth of cut (C) and feed per tooth (D) are the leading direct factors affecting $\eta_{\mathrm{s}}$. Knowing that the tested materials are from different families, the statistical significance could be attributed to mechanical properties of the tested materials, such as ductility and brittleness which may pose variation in burr formation shapes and mechanism. As shown in Figure 6, higher levels of cutting speed, feed per tooth and depth of cut led to increased $\eta_{\mathrm{s}}$. This denotes more required efforts for deburring and edge finishing. As shown in Figure 6, under the similar cutting condition, the higher resulting value of $\eta_{\mathrm{s}}$ is observed in AA7075-T6 (Fig.7 and Table 1) which is, however, harder than AA 2024-T351 (Tiabi 2010).

As noted in (Niknam et al. 2013), under similar cutting conditions as presented in this work, exit, top and entrance burrs are governed by different cutting parameters. This phenomenon can be related to material properties, burr formation mechanism, as well as the tool geometry and coating used. In fact, when cutting tools with multiple teethes are used, heat generation increases, in particular in highspeed machining. This phenomenon may lead to tearing off a part of the burr, accumulated on the top side and finally sticks it into the side face of the machining part. Furthermore, because of the yield strength, which is higher in AA 7075-T6 than in Al 2024-T351 (Table 2), more burrs appear on the work parts edges which led to higher resulting values of $\eta$ s under similar cutting conditions (Figure 6and Figure 8).

As noted in (Niknam 2017), another major element which plays a critical role on burr formation morphology and size is friction. Increased friction during machining operation increases the incidence 
of burr formation which eventually leads to more complex deburring operation. In fact, the effects of friction can be divided into three basic mechanisms, one due to asperity deformation, one due to adhesion and one due to particle ploughing. In orthogonal milling, friction coefficient $(\mu)$ can be approximated as (San-Juan et al. 2010):

$$
\mu=\tan (\varphi)=F_{r} \times F_{t}^{-1}
$$

Where:

$\varphi$ : immersion angle

$F_{r}$ : radial cutting force

$F_{r}$ : Tangential cutting force

According to Eq.(2), when the tool faces friction decreases, there is a corresponding increase in the shear angle $(\Phi)$ and the accompanying reduction of the chip thickness $h(\varphi)$. Consequently, the plastic strain associated with chip formation is reduced and longer and thicker $\mathrm{B}_{2}$ and shorter and thinner $B_{1}$ are expected. Higher levels of cutting speed and insert nose radius (RE) leads to increased $F_{r}$ to a large extent, particularly where the depth of cut is smaller than the insert nose radius (Re). In addition, materials with higher machinability generate more $F_{r}$, which may lead into a reduction of friction between the chip and tool (San-Juan et al. 2010) . Furthermore, during the milling operation, slight plastic deformation, serious rubbing and ploughing effects are taking place which causes heat generation, especially when high-speed cutting is used. This may lead to the formation of larger burrs on the exit side of the work parts. A complete overview of friction effects on orthogonal milling exit burrs is presented in (Niknam 2017). A comprehensive overview of the procedure used to proposed Eq.(2) is presented in (Niknam et al. 2014).

Referring to individual analysis of $\eta_{\mathrm{s}}$ in each material presented in Figure 7, it can be stated that depth of cut and feed per tooth are the non-statistically significant parameters on AA 2024-T351 and AA 7075-T6, respectively. However, cutting speed and cutting tool are still considered as the 
statisticaly significant parameters on $\eta_{\mathrm{s}}$ in both tested materials. The effects of cutting tools may be attributed to coating and insert nose radius which seems to vary the burr formation morphology and size. This is in agreement with observations made in (Niknam 2013; Niknam et al. 2013a). As shown in Figure 6b, the cutting tool with smaller insert nose radius $R \varepsilon$ (Tool 2) led to lower resulting values of $\eta_{\mathrm{s}}$. Moreover, higher cutting speed generates more cutting force in feed direction and eventually larger exit down bottom burrs are generated (Niknam et al. 2013a; Niknam et al. 2014d). This may lead to higher resulting values of burr edge occupancy $\eta_{\mathrm{s}}$. According to Figure 8, using low levels of feed rate and cutting speed may lead to almost $50 \%$ reduction in calculated value of $\eta_{\mathrm{s}}$ in AA 2024T351 as well as around 10\% in AA7075-T6 (Figure 8). This denotes that higher levels of cutting speed are suitable for brittle materials (AA 2024-T351) than that observed in ductile materials (AA07075-T6). As noted in (Niknam et al. 2015), this trend can be attributed to friction generation which in fact tends to affects the burr formation mechanism, shape and size as well as cutting forces.

\section{Conclusion}

- Burr size reduction or localizing the burrs in inaccessible locations tend to simplify the deburring operations and in fact less manufacturing expenses are expected. It is therefore required to propose innovate parameters which can be controlled by the cutting parameters while can also be used as an index to select adequate deburring methods. To that end and in order to investigate the adequate solutions to achieve edges with minimum burrs a new index, so-called burr edge occupancy $\eta_{\mathrm{s}}$ was proposed in this work.

- Despite the material used, it was observed that $\eta_{\mathrm{s}}$ is statistically controllable by the most of cutting parameters used, in particular, cutting tool and cutting speed and family of material. The effects of cutting speed on $\eta_{\mathrm{s}}$ vary according to the family of material and mechanical properties, in principle brittleness and ductility. 
- It was observed that low levels of cutting speed and feed rate might lead to reduced burr edge occupancy $\eta_{\text {s }}$ by $50 \%$ on AA $2024-\mathrm{T} 351$ and $10 \%$ on AA $7075-\mathrm{T} 6$, which is, however, harder than the latter.

- As noted earlier, high cutting speed is more recommended on brittle materials than ductile materials. The significant effect of coating on $\eta_{\mathrm{s}}$ was discovered. The cutting tools with smaller insert nose radius $R \varepsilon$ led to lower resulting values of $\eta_{\mathrm{s}}$.

- Generating a direct link between $\eta_{\mathrm{s}}$ and the widely used deburring methods is the main aspect of future works. Furthermore, the similar methodology can be conducted for different types of machining operations, in principle face milling and drilling operations as well as the various family of materials. Moreover, the proposed index can be improved by incorporating the effects of major elements affecting the burr formation morphology and size, in principle ductility of materials as well as friction generation during the cutting process.

\section{Acknowledgment}

Authors would like to acknowledge the financial support received by the Fonds Québécois de la Recherche sur la Nature et les Technologies (FQRNT) and Iran's National Elites Foundation. 


\section{References}

Aurich, JC., Dornfeld, D.,Arrazola, P. J., Franke, V., Leitz , L. and Min, S. (2009). Burrs-Analysis, control and removal. CIRP Annals - Manufacturing Technology 58(2): 519-542.

Biermann, D. and Heilmann, M. (2010).Burr Minimization Strategies in Machining Operations. BurrsAnalysis, Control and Removal: Part 1, 13-20.

Chen, M., Liu, G. and Shen, Z. (2006) Study on Active Process Control of Burr Formation in Al-Alloy Milling Process. Proceeding of the IEEE, International Conference on Automation Science and Engineering, 8-10 Oct. 2006, Shanghai, China.

Chern, GL. (2006). Experimental observation and analysis of burr formation mechanisms in face milling of aluminum alloys. International Journal of Machine Tools and Manufacture 46(12-13): 1517-1525.

Committee, AIH. and Knovel (2004). ASM Handbook: Metallography and Microstructures, ASM International.

Dornfeld, D. and Avila, M (2004). On the face milling burr formation mechanisms and minimization strategies at high tool engagement. Consortium on deburring and edge finishing. University of California, Berkeley, CA.

Gillespie, L. (1999). Deburring and edge finishing handbook. Dearborn, MI ,USA, Society of Manufacturing Engineers (SME).

Gillespie, L. and Blotter, P. (1976). Formation and properties of machining burrs. J. Eng. Ind.(Trans. ASME, B) 98(1): 66-74.

Hashimura, M. and Dornfeld, D. (1995). Analysis of burr formation mechanism in machining process. Technical paper, society of manufacturing engineering (SME)-All series.

Iwata, K., Osakada, K. and Terasaka, Y (1984). Process modeling of orthogonal cutting by the rigid-plastic finite element method. Journal of Engineering materials and technology 106: 132-138.

Klocke, F., Hoppe,S .and Fritsch, R. (2004). FE-modeling of burr formation in orthogonal cutting. Proceeding of 7th Int. Conference on Deburring and Surface Finishing, University of California, Berkeley, USA.

Ko, S. and Dornfeld, D. (1991). A study on burr formation mechanism." Journal of Engineering materials and technology 113(1): 75-87.

Korkut, I. and Donertas, M. (2007). The influence of feed rate and cutting speed on the cutting forces, surface roughness and tool-chip contact length during face milling. Materials \& design 28(1): 308-312.

Lauderbaugh, L. (2009). Analysis of the effects of process parameters on exit burrs in drilling using a combined simulation and experimental approach. Journal of Materials Processing Technology 209(4): 1909-1919.

Lekkala, R., Bajpai, V., Singh, RK. and Joshi, S. S. (2011). Characterization and modeling of burr formation in micro-end milling.Precision Engineering 35(4): 625-637.

Leopold, J. and Wohlgemuth, R. (2010). Modeling and Simulation of Burr Formation: State-of-the-Art and Future Trends. Burrs-Analysis, Control and Removal: 79-86.

Lin, TR. (2000). Experimental study of burr formation and tool chipping in the face milling of stainless steel." Journal of Materials Processing Technology 108(1): 12-20.

Luo, M., Liu, G. and Chen,M. (2008). Mechanism of burr formation in slot milling Al-alloy. International Journal of Materials and Product Technology 31(1): 63-71. 
Nakayama, K. and Arai,M (1987). Burr formation in metal cutting. CIRP Annals-Manufacturing Technology 36(1): 33-36.

Narayanaswami, R. and Dornfeld,D. (1994). Design and process planning strategies for burr minimization and deburring.Transactions of the North American Manufacturing Research Institute of SME 1994. 22: 313-322.

Niknam, SA. (2013). Burrs Understanding, Modeling and Optimization during Slot Milling of Aluminium Alloys

Niknam, SA. (2017). Modeling and experimental characterization of the friction effects on orthogonal milling exit burrs.The International Journal of Advanced Manufacturing Technology 91(1): 1079-1089.

Niknam, SA., Zedan,Y and Songmene,V (2012). Burr formation during milling of wrought aluminum alloys. 20th ISME Annual International Conference on Mechanical Engineering. 16-18 May 2012, Shiraz, Iran.

Niknam, SA., Zedan, Y and Songmene,V. (2014a). Machining Burrs Formation \& Deburring of Aluminium Alloys Light Metal Alloys Applications 99-122.

Niknam, SA., Khettabi,R. and Songmene,V. (2014b). Machinability and Machining of Titanium Alloys: A Review. Machining of Titanium Alloys, Springer Berlin Heidelberg: 1-30.

Niknam, SA., Wygowski,W., Balazinski,M and Songmene, V. (2014c). Milling Burr Formation and Avoidance. Machinability of Advanced Materials. J. P. Davim. London, UK, ISTE Wiley: 57-94.

Niknam, SA. and Songmene, V. (2013a). Experimental Investigation and Modeling of Milling Burrs. ASME 2013 International Manufacturing Science and Engineering Conference collocated with the 41st North American Manufacturing Research Conference, 10-14 June 2013,Madison,Wisconsin, USA.

Niknam, SA. and Songmene, V. (2013b). Factors governing burr formation during high-speed slot milling of wrought aluminium alloys. Proceeding of the Institution of Mechanical Engineers, Part B: Journal of Engineering Manufacture 227(8): 1165-1179.

Niknam, SA. and Songmene,V. (2013c). Modeling of burr thickness in milling of ductile materials. The International Journal of Advanced Manufacturing Technology 66(9): 2029-2039.

Niknam, SA. and Songmene, V. (2013d). Simultaneous optimization of burrs size and surface finish when milling 6061-T6 aluminium alloy. International Journal of Precision Engineering and Manufacturing 14(8): 1311-1320.

Niknam, SA. and Songmene,V. (2014d). Analytical modelling of slot milling exit burr size. The International Journal of Advanced Manufacturing Technology 73(1-4): 421-432.

Niknam, SA. and Songmene,V. (2015). Milling Burr Formation, Modeling and Control: A Review .Institution of Mechanical Engineers, Part B: Journal of Engineering Manufacture 229(6): 893-909.

Niknam, SA. and Songmene, V. (2017). Burr formation and correlation with cutting force and acoustic emission signals. Proceedings of the Institution of Mechanical Engineers, Part B: Journal of Engineering Manufacture 231(3): 399-414.

Olvera, O. and Barrow, G. (1996). An experimental study of burr formation in square shoulder face milling. International Journal of Machine Tools and Manufacture 36(9): 1005-1020.

Rangarjan, A. (2005). Optimization of face milling process- Tool path and process planning techniques, Ph.D Thesis, University of California at Berkeley, USA.

San-Juan, M.,Martín, Ó and Santos, F. (2010). Experimental study of friction from cutting forces in orthogonal milling. International Journal of Machine Tools and Manufacture 50(7): 591-600. 
Schäfer, F. (1975). Entgraten, Krausskopf.

Songmene, V., Kouam, J., Zaghbani, I., Parson, N and Maltais, N (2013). Global Machinability of Al-Mg-Si Extrusions. Aluminium Alloys - New Trends in Fabrication and Applications. P. Ahmad Zaki, InTech.

Tiabi, A. (2010). Formation des bavures dùsinage et finition de pieces Master of Science, École de technologie superieure.

\section{List of Tables}

Table 1. Cutting parameters used

Table 2. Mechanical properties of studied aluminum alloys (Committee et al. 2004)

\section{List of Figures}

Figure 1 : Slot Milling Burrs (adapted from (Niknam et al. 2013a))

Figure 2.Slot milled 6061-T6 aluminum machined part with (a) large burrs (b) acceptable burr size (Niknam et al. 2013a))

Figure 3. Measurement values of burr (Niknam 2013)

Figure 4. The main components of the burr edge occupancy $\eta \mathrm{s}$

Figure 5. Experimental devices: (a) 3-Axis CNC machine (b) Cutting tool used (c) Work parts configuration Figure 6. (a) Pareto chart of $\eta_{s}\left(R^{2}=0.75\right)$; (b) Main effect plot of $\eta s$

Figure 7. Pareto chart of $\eta \mathrm{s}$ in (a) AA 2024-T351 $\left(\mathrm{R}^{2}=0.79\right)$ (b) AA $7075-\mathrm{T} 6\left(\mathrm{R}^{2}=0.77\right)$

Figure 8. 3D contour plot of $\eta$ s under for (a) AA 2024-T351; (b) AA 7075-T6 when using the depth of cut 1 $\mathrm{mm}$ and tool \#1 


\section{Table 1}

\begin{tabular}{|l|c|c|c|}
\hline \multirow{2}{*}{ Experimental parameters } & \multicolumn{3}{|c|}{ Level } \\
\cline { 2 - 4 } & $\mathbf{1}$ & $\mathbf{2}$ & $\mathbf{3}$ \\
\hline A: Material & $2024-\mathrm{T} 351$ & - & $7075-\mathrm{T} 6$ \\
\hline B: Cutting tools $/$ Coating & $\mathrm{TiCN}$ & TiAlN & TiCN $+\mathrm{Al}_{2} \mathrm{O}_{3}+\mathrm{TiN}$ \\
\hline Insert nose radius $(\mathrm{mm})$ & 0.5 & 0.81 & 0.5 \\
\hline C: Depth of cut, $a_{p}(\mathrm{~mm})$ & 1 & - & 2 \\
\hline D: Feed per tooth $f_{z}(\mathrm{~mm} / \mathrm{z})$ & 0.01 & 0.055 & 0.1 \\
\hline E: Cutting speed $v_{c}(\mathrm{~m} / \mathrm{min})$ & 300 & 750 & 1200 \\
\hline
\end{tabular}

\section{Table 2}




\begin{tabular}{lccc}
\hline Material & \multicolumn{3}{c}{ Mechanical Properties } \\
\cline { 2 - 4 } & Brinell Hardness & Yield Strength & Elongation at Break \\
\hline Al 7075-T6 & 150 & $550 \mathrm{MPa}$ & $11(\%)$ \\
Al 2024- T351 & $120 \mathrm{HB}$ & $325 \mathrm{MPa}$ & $20(\%)$ \\
\hline
\end{tabular}




\section{Figure1}

\begin{tabular}{|c|l|}
\hline List & Burr name \\
\hline$B_{1}$ & Exit up milling side \\
\hline$B_{2}$ & Exit bottom side \\
\hline$B_{3}$ & Exit down milling side \\
\hline$B_{4}$ & Top-down milling side \\
\hline$B_{5}$ & Entrance down milling side \\
\hline$B_{6}$ & Entrance bottom side \\
\hline$B_{7}$ & Entrance up milling side \\
\hline$B_{8}$ & Top up milling side \\
\hline
\end{tabular}

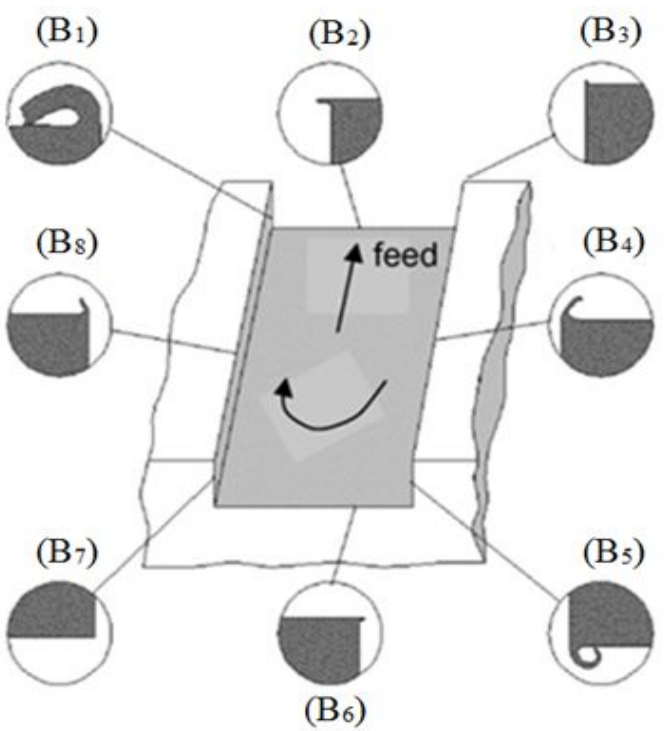

Figure 2 


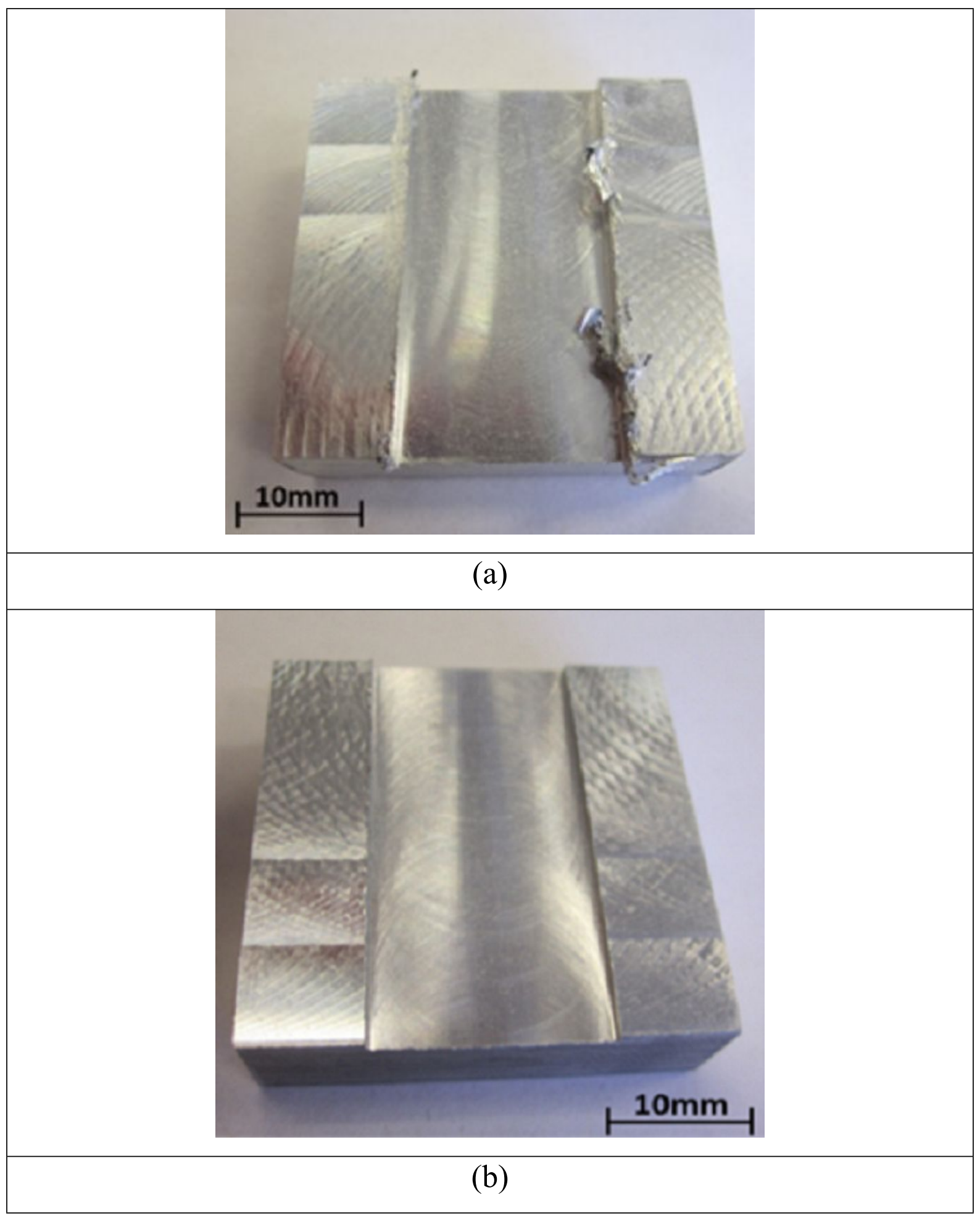

\section{Figure 3}




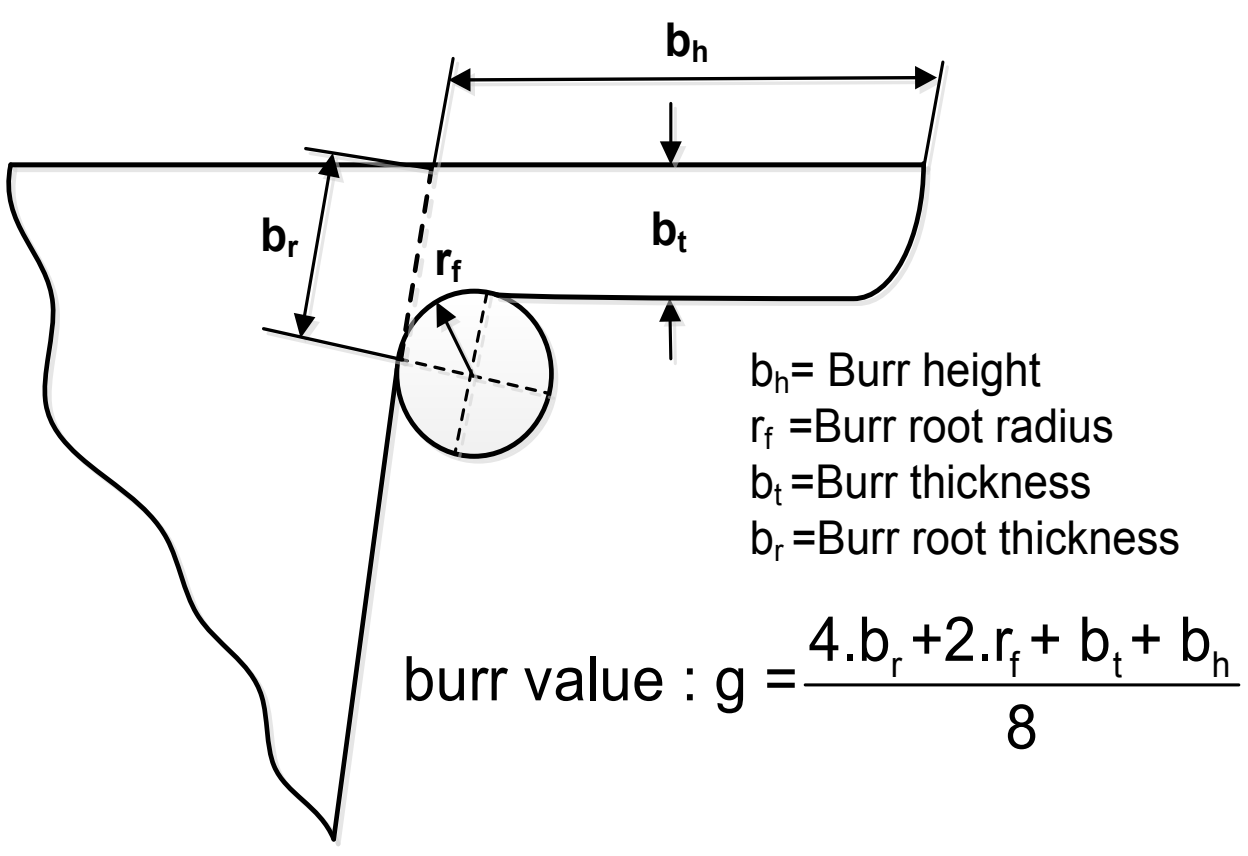

Figure 4 


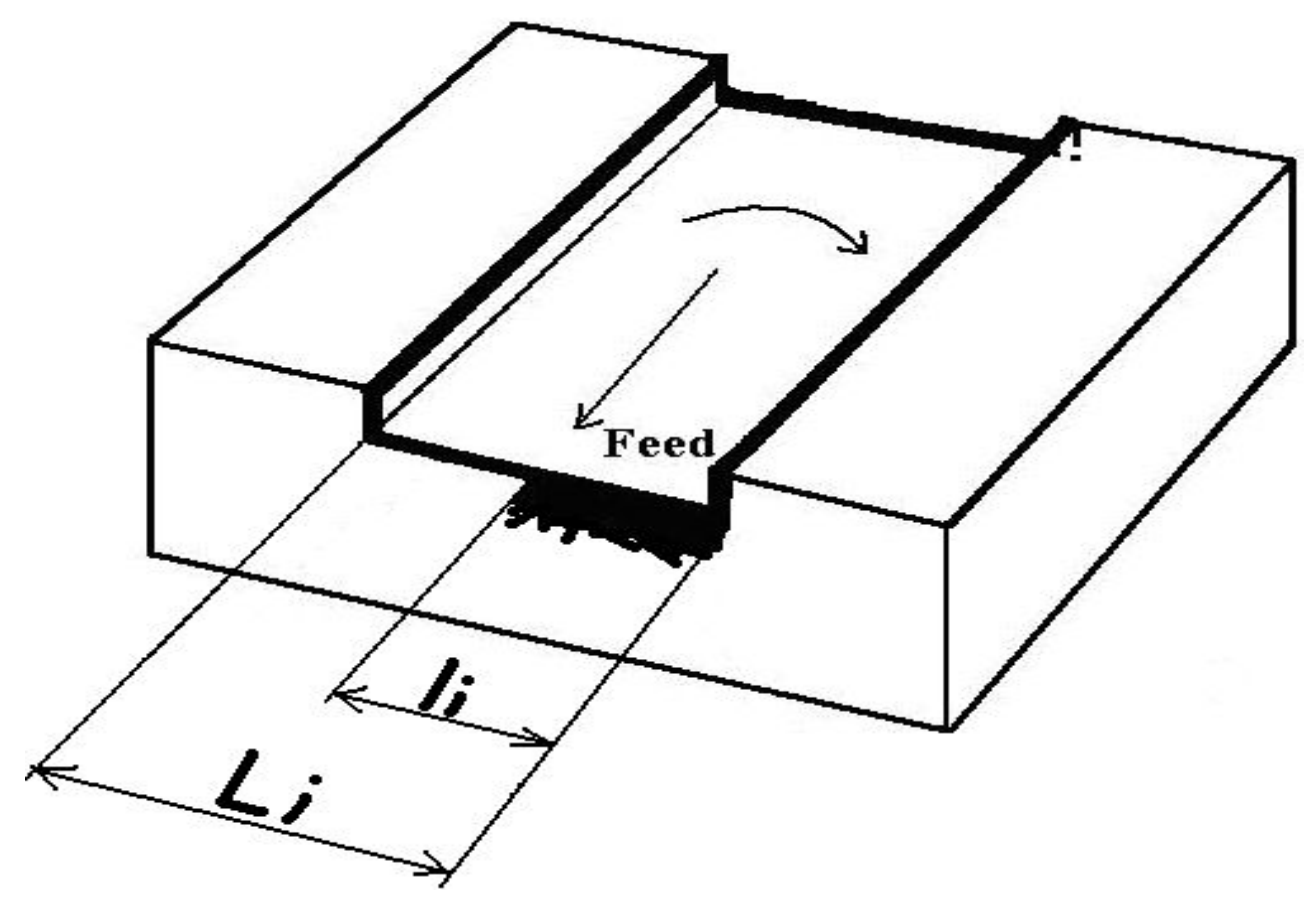

Figure 5 


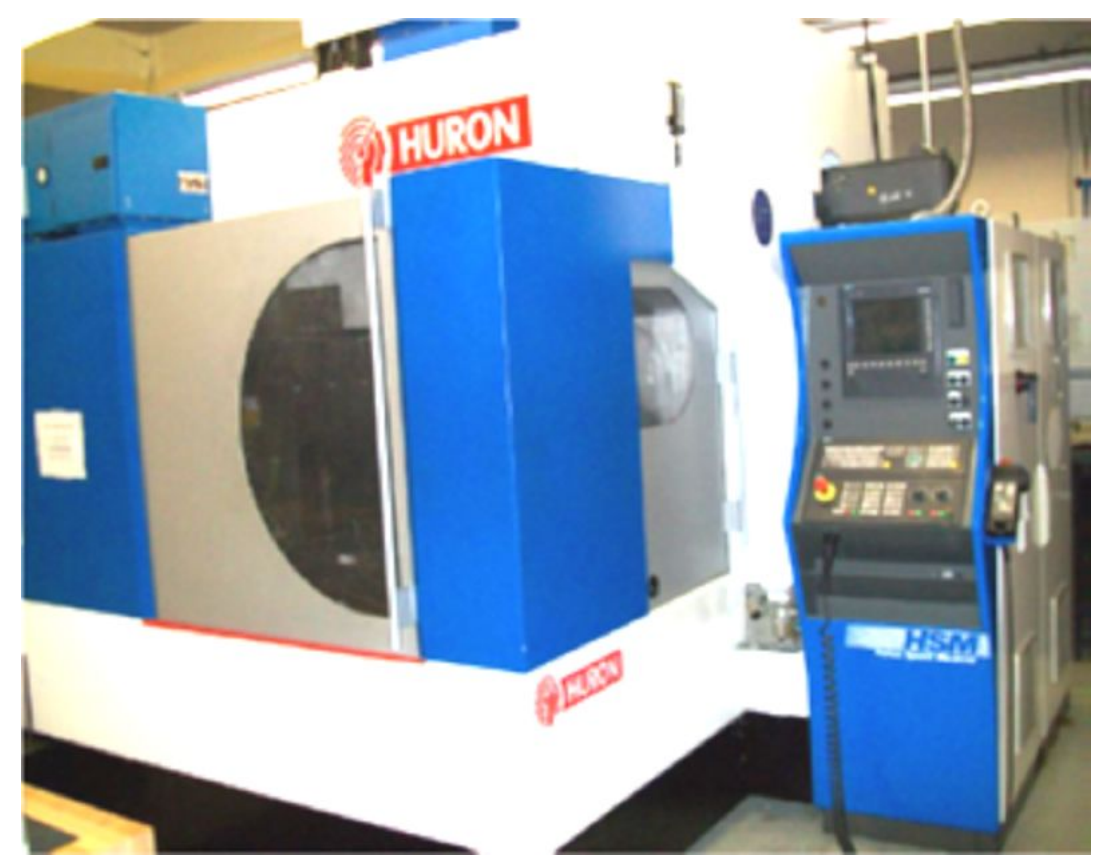

5(a)

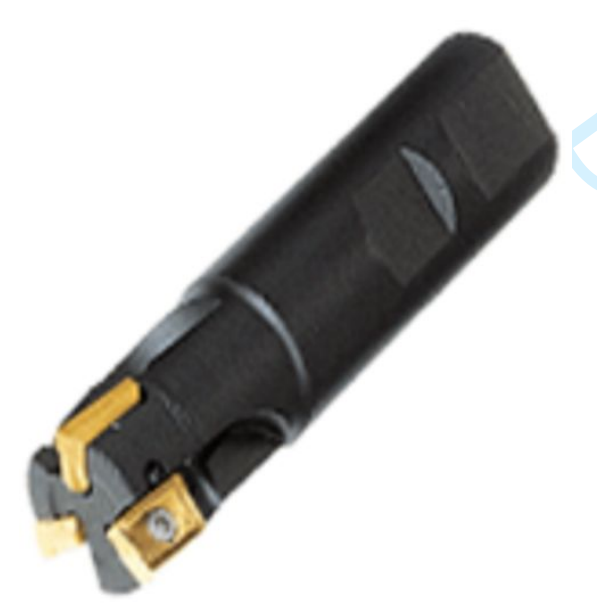

5(b)

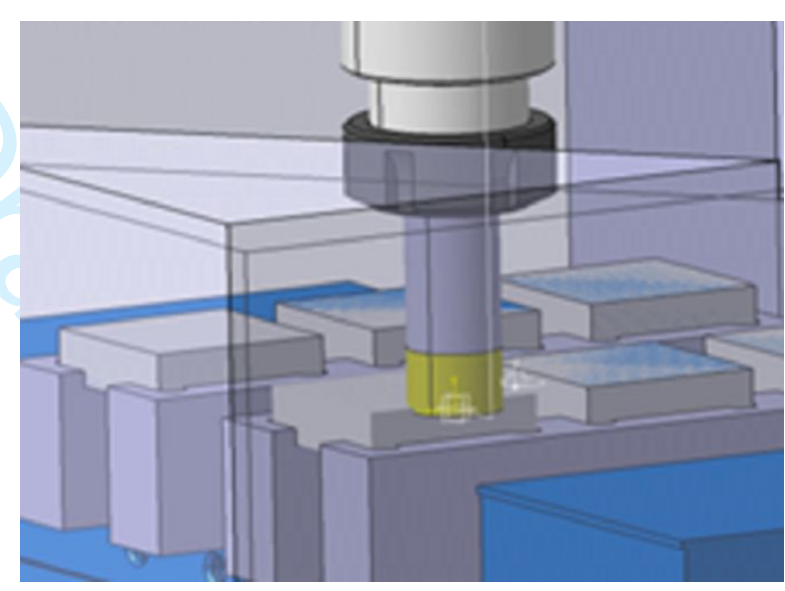

5(c)

\section{Figure 6}




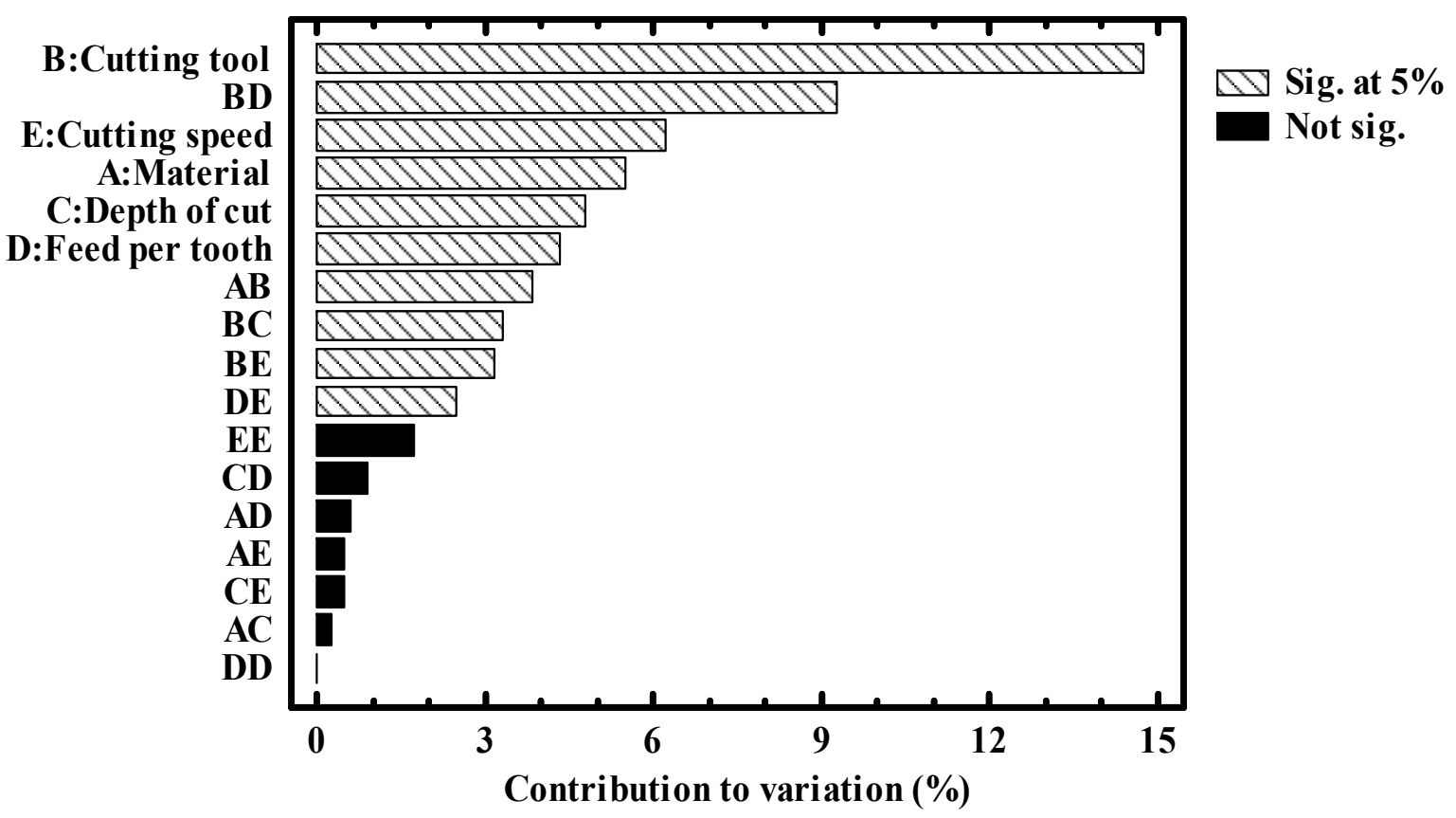

(a)

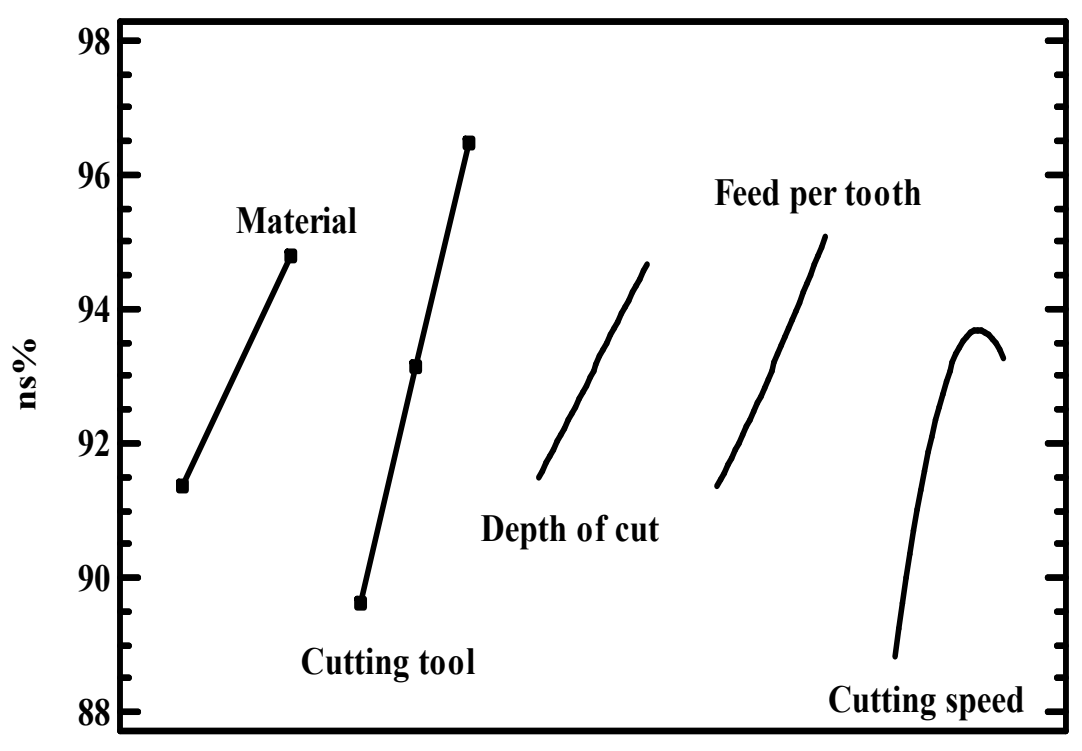

(b)

\section{Figure 7}




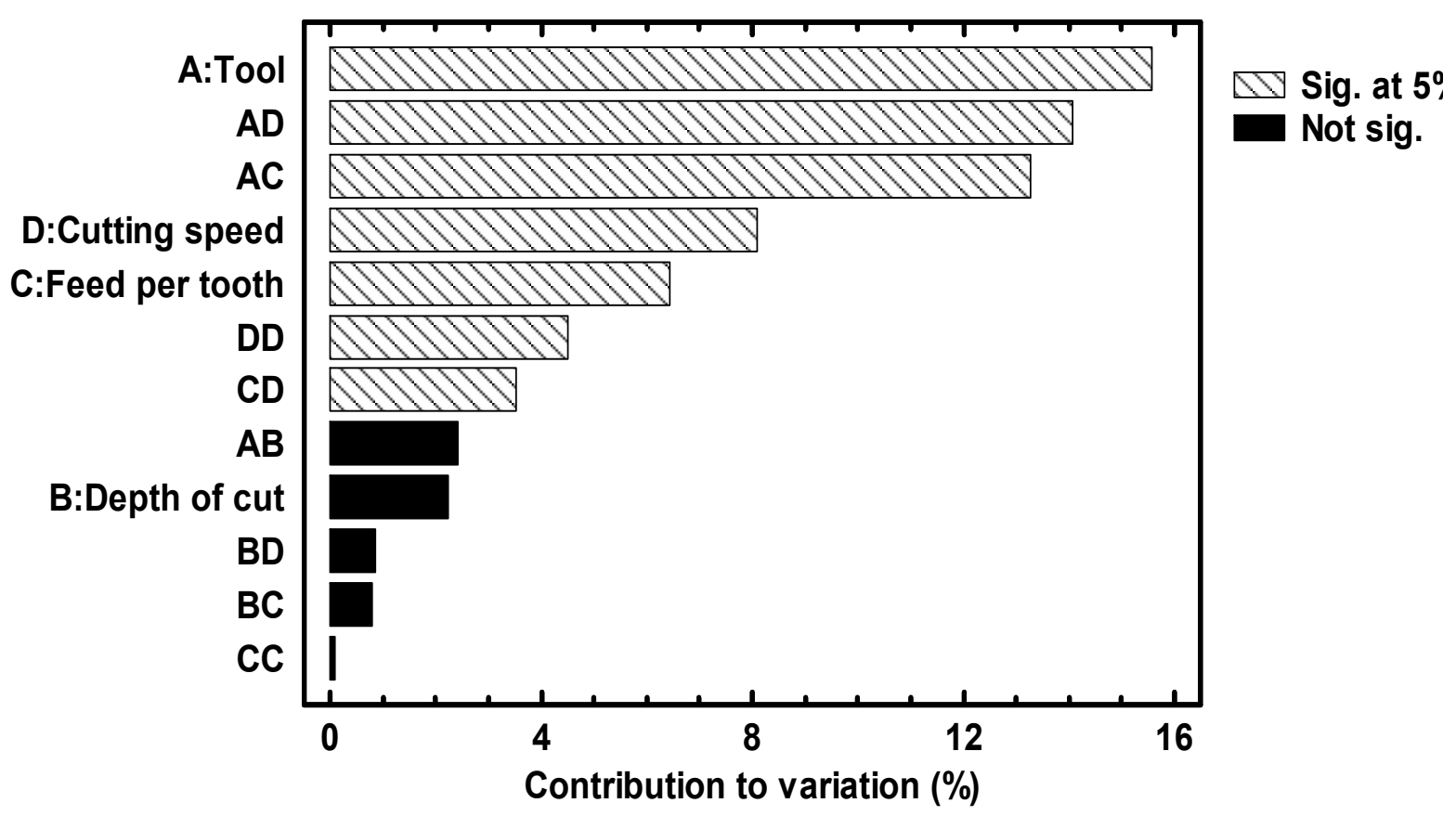

(a)

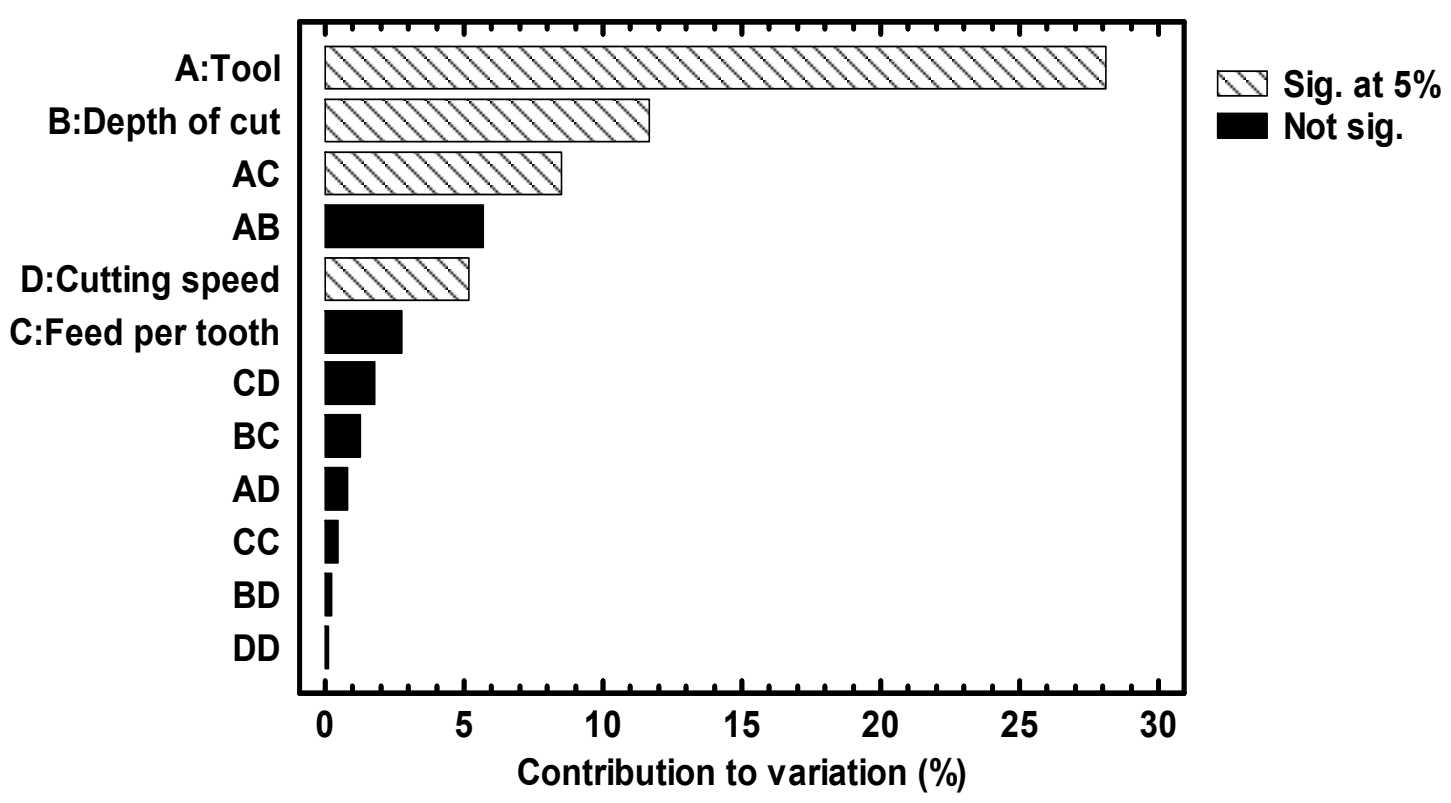

(b)

\section{Figure 8}




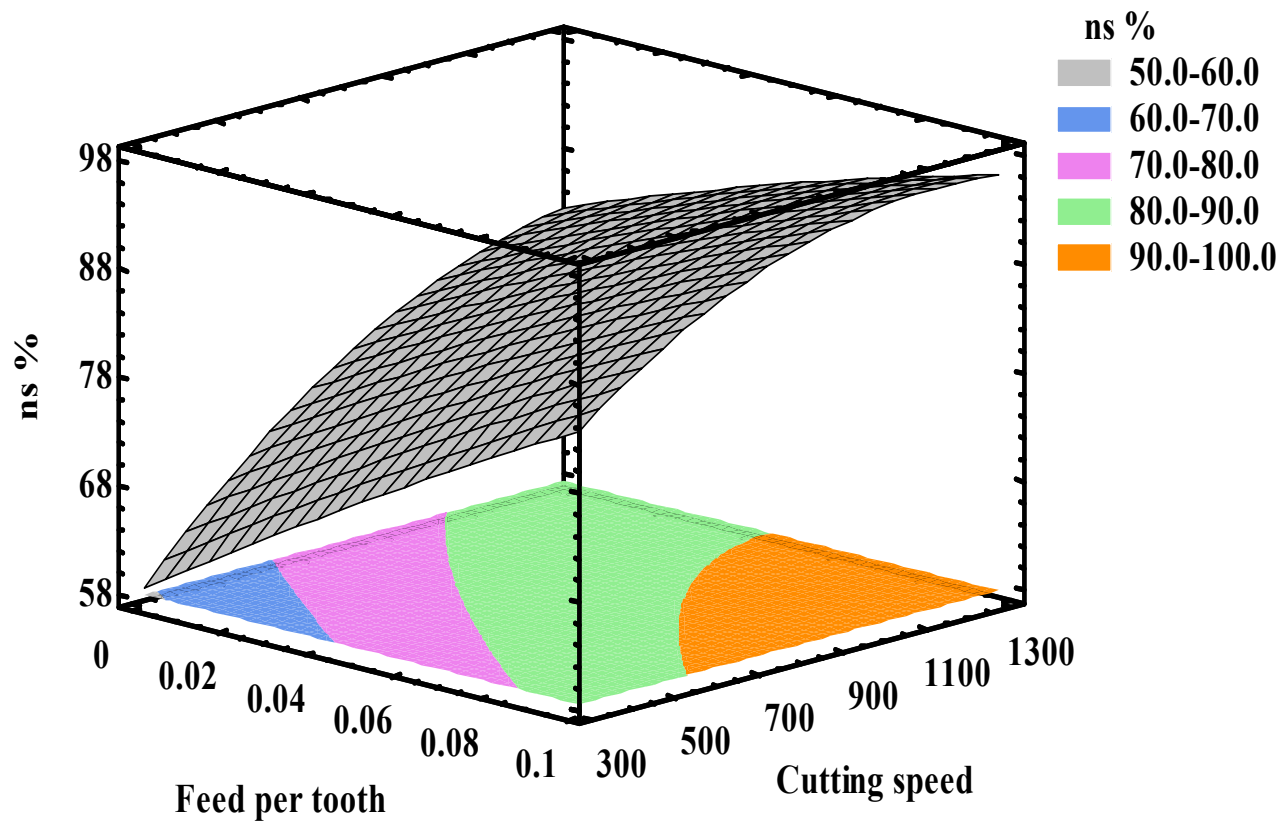

(a)

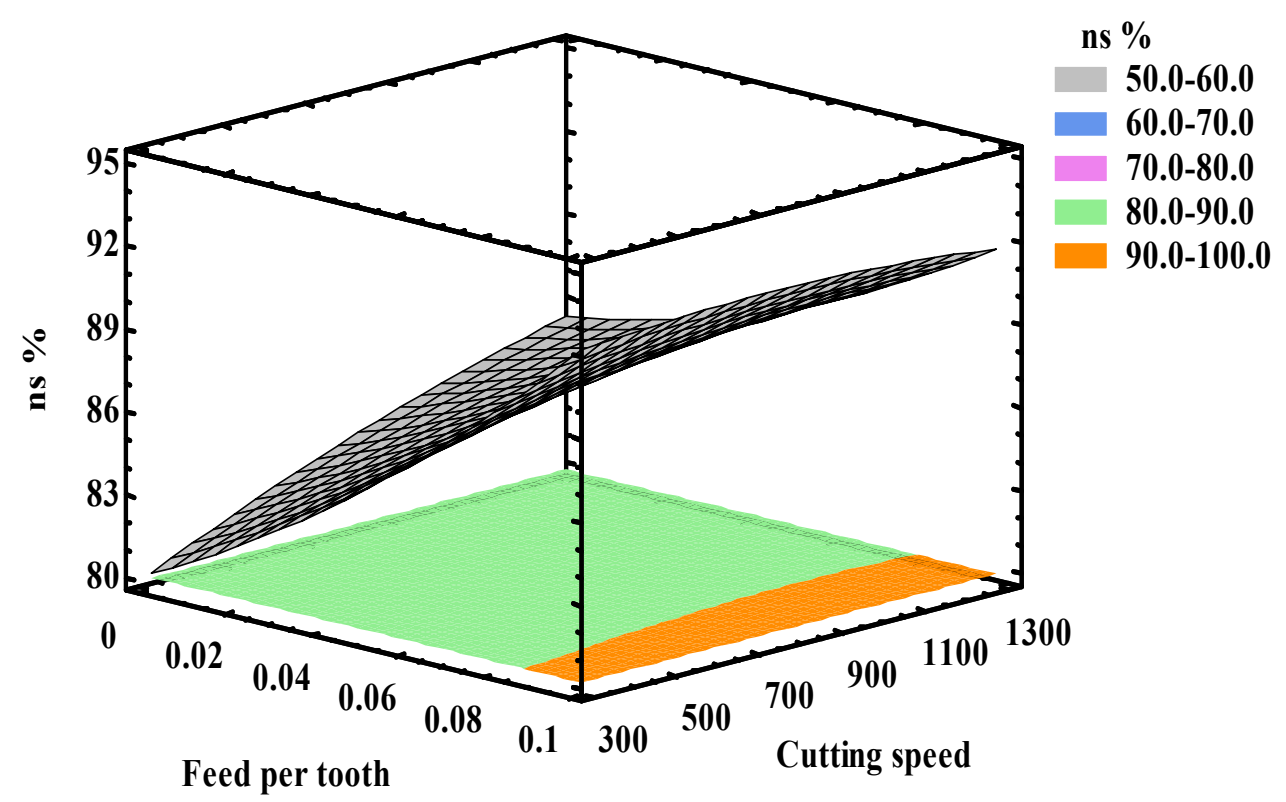

(b) 


\begin{tabular}{|c|c|c|}
\hline \multirow[t]{2}{*}{ Test No. } & \multicolumn{2}{|c|}{$\eta_{\mathrm{s}} \%$} \\
\hline & AA 2024-T351 & AA 7075-T6 \\
\hline 1 & 50.000 & 83.621 \\
\hline 2 & 81.034 & 83.621 \\
\hline 3 & 79.310 & 83.621 \\
\hline 4 & 83.621 & 83.621 \\
\hline 5 & 90.517 & 83.621 \\
\hline 6 & 91.379 & 83.621 \\
\hline 7 & 83.621 & 91.379 \\
\hline 8 & 90.517 & 97.414 \\
\hline 9 & 93.966 & 96.552 \\
\hline 10 & 61.864 & 99.153 \\
\hline 11 & 92.373 & 83.898 \\
\hline 12 & 95.763 & 98.305 \\
\hline 13 & 78.814 & 91.525 \\
\hline 14 & 91.525 & 93.220 \\
\hline 15 & 90.678 & 98.305 \\
\hline 16 & 94.068 & 98.305 \\
\hline 17 & 92.373 & 94.915 \\
\hline 18 & 98.305 & 96.610 \\
\hline 19 & 87.069 & 87.931 \\
\hline 20 & 87.931 & 88.793 \\
\hline 21 & 93.103 & 100.000 \\
\hline 22 & 90.517 & 91.379 \\
\hline 23 & 91.379 & 83.621 \\
\hline 24 & 100.000 & 87.931 \\
\hline 25 & 89.655 & 87.069 \\
\hline 26 & 88.793 & 91.379 \\
\hline 27 & 92.241 & 90.517 \\
\hline 28 & 88.983 & 88.983 \\
\hline 29 & 100.000 & 100.000 \\
\hline 30 & 91.525 & 93.220 \\
\hline 31 & 94.915 & 90.678 \\
\hline 32 & 92.373 & 100.000 \\
\hline 33 & 89.831 & 94.068 \\
\hline 34 & 94.915 & 89.831 \\
\hline 35 & 95.763 & 92.373 \\
\hline 36 & 90.678 & 90.678 \\
\hline 37 & 89.655 & 87.931 \\
\hline 38 & 100.000 & 99.138 \\
\hline 39 & 91.379 & 100.000 \\
\hline 40 & 93.103 & 95.690 \\
\hline 41 & 88.793 & 100.000 \\
\hline 42 & 89.655 & 98.276 \\
\hline
\end{tabular}




\begin{tabular}{|c|c|c|}
$\mathbf{4 3}$ & 91.379 & 96.552 \\
\hline $\mathbf{4 4}$ & 95.690 & 100.000 \\
\hline $\mathbf{4 5}$ & 95.690 & 99.138 \\
\hline $\mathbf{4 6}$ & 91.525 & 90.678 \\
\hline $\mathbf{4 7}$ & 100.000 & 98.305 \\
\hline $\mathbf{4 8}$ & 91.525 & 100.000 \\
\hline $\mathbf{4 9}$ & 93.220 & 98.305 \\
\hline $\mathbf{5 0}$ & 94.068 & 100.000 \\
\hline $\mathbf{5 1}$ & 83.898 & 100.000 \\
\hline $\mathbf{5 2}$ & 91.525 & 100.000 \\
\hline $\mathbf{5 3}$ & 93.220 & 97.458 \\
\hline $\mathbf{5 4}$ & 92.373 & 99.153 \\
\hline
\end{tabular}

